\title{
PENGEMBANGAN PASAR RAKYAT BERBASIS KEPARIWISATAAN BUDAYA BALI
}

\author{
Ida Ayu Made Dwi Susanti ${ }^{1}$, Universitas Mahasaraswati Denpasar, \\ dwisusanti1989@unmas.com \\ Ni Putu Anglila Amaral', Universitas Mahasaraswati Denpasar, \\ anglilaamaral@unmas.ac.id
}

Vol. 35 No. 1 (2021): p 37-45

Submitted: March 16 ${ }^{\text {nd }}, 2021$

Accepted: June $7^{\text {th }}, 2021$

\section{Keywords: \\ Balinese Cultural \\ Tourism; People's \\ Market}

\begin{abstract}
The people's market is one of the places to distribute and market agricultural, food and non-agricultural products. This market is one of the most obvious indicators to see the standard of living of the surrounding communities. The people's market does not only involve economic actors in the agricultural and food sectors but also those in non-agricultural sectors. The agricultural sector development approach that is still being implemented today is agribusiness system. The people's market is part of the agribusiness system, which is included in the subsystem of supporting institutions. This subsystem provides services for upstream agro-industry subsystem, downstream agribusiness subsystem, and marketing subsystem so as to ensure smooth transactions between producers and consumers.
\end{abstract}

\section{Kata kunci:}

Kepariwisataan

Budaya Bali; Pasar

Rakyat

\begin{abstract}
Pasar rakyat merupakan salah satu wadah dalam menyalurkan dan memasarkan produk-produk pertanian, pangan, dan non. Pasar rakyat menjadi salah satu indikator paling nyata untuk melihat taraf kehidupan ekonomi masyarakat sekitar. Pasar rakyat tidak hanya melibatkan para pelaku ekonomi di sektor pertanian dan pangan tetapi juga non pertanian. Pendekatan pembangunan sektor pertanian yang masih dilakukan sampai saat ini yaitu pendekatan melalui sistem agribisnis. Pasar Rakyat merupakan bagian dari sistem agribisnis yaitu termasuk dalam subsistem lembaga penunjang. Subsistem lembaga penunjang menyediakan jasa bagi subsistem agroindustri hulu, subsistem agribisnis hilir, dan subsistem pemasaran agar transaksi antara produsen dan konsumen dapat berjalan dengan lancar.
\end{abstract}




\section{PENDAHULUAN}

Pasar rakyat merupakan salah satu wadah bagi UMKM dalam menyalurkan dan memasarkan produk-produk pertanian, pangan, dan non pertanian sehingga penyerapan tenaga kerja oleh pasar rakyat sangat besar. Secara sederhana dapat dihitung penyerapan yang dihitung oleh aktivitas pasar rakyat (Firmanzah \& Halim, 2012) mengasumsikan jika satu pasar rakyat terdiri dari 250 orang pedagang, dimana setiap los atau kios mempekerjakan 2-3 orang karyawan maka jumlah tenaga kerja yang terserap mencapai 500-750 juta orang per pasar. Belum termasuk aktivitas pendukung seperti tukang angkut, ojek, tukang parkir, dan pedagang kaki lima.

Pasar rakyat adalah salah satu indikator yang dapat digunakan untuk melihat keadaan ekonomi masyarakat sekitar. Pasar rakyat tidak hanya melibatkan para pelaku ekonomi di sektor pertanian dan pangan tetapi juga non pertanian seperti pelaku jasa keuangan dan pelaku jasa angkutan yang secara tidak lansung keberadaannya sangat berjasa. Pendekatan pembangunan sektor pertanian yang masih dilakukan sampai saat ini yaitu pendekatan melalui sistem agribisnis.

Sistem agribisnis lebih menekankan pada tiga hal yaitu dari pendekatan produksi ke pendekatan berorientasi kepada bisnis, pembangunan lintas sektoral (agroindustri hulu, agroindustri hilir, dan lembaga jasa penunjang) dan pembangunan sistem agribisnis sebagai pembangunan wilayah. Sistem agribisnis (Antara, 2009) terdiri atas subsistem produksi, subsistem pengolahan (agroindustri hulu-hilir), subsistem pemasaran dan lembaga penunjang. Subsistem lembaga penunjang menyediakan jasa bagi subsistem agroindustri hulu, subsistem, agribisnis hilir, dan subsistem pemasaran agar transaksi antara produsen dan konsumen dapat berjalan dengan lancar. Subsistem lembaga penunjang terdiri atas wujud infrastruktur dan wujud organisasi seperti pasar rakyat, koperasi, jalan, jembatan, dan pasar induk.

Menurunnya eksistensi pasar rakyat telah dirasakan diseluruh wilayah di Indonesia salah satunya adalah di Provinsi Bali. Hal ini, dapat dilihat dari semakin meningkatnya kehadiran pasar modern di Bali, seperti swalayan dan minimarket. Peningkatkan ini merupakan proses modernisasi masyarakat seiring dengan peningkatan daya beli masyarakat dan "gengsi" dalam berbelanja di pasar swalayan. Pasar swalayan menjadi salah satu destinasi berbelanja (one stop shopping) bagi masyarakat dan wisatawan. Peningkatan daya beli merupakan dampak dari 
peningkatan kesejahteraan masyarakat dan peningkatan peluang kerja yang berdampak dari perkembangan pariwisata Bali.

Perkembangan sektor pariwisata di Bali dirasa semakin tidak selaras dengan perkembangan pertanian Bali. Kontribusi sektor pariwisata dan pertanian semakin menunjukkan adanya ketimpangan dimana kontribusi sektor pertanian semakin terpuruk sedangkan kontribusi sektor pariwisata semakin meningkat terhadap PDRB Provinsi Bali (Produk Domestik Regional Bruto). Peranan sektor pertanian dan pariwisata dalam PDRB Provinsi Bali, kontribusi sektor pertanian mengalami penurunan terhadap Produk Regional Domestik Bruto (PRDB) Provinsi Bali selama periode 2010 sampai 2016. Perkembangan data statisik pada kedua sektor tersebut yaitu kontribusi sektor pertanian mengalami penurunan dari 17,7 persen pada tahun 2010 menjadi 14,47\% pada tahun 2016, sedangkan kontribusi sektor pariwisata mengalami peningkatan dari 19,12 tahun 2010 menjadi 28,2 persen tahun 2016 (Biro Pusat Statistik, 2017).

Untuk dapat meningkatkan peranan pasar rakyat, pemerintah Provinsi Bali, mulai merevitalisai pasar rakyat untuk menunjukkan daya saing pasar rakyat. Pasar rakyat di Provinsi Bali perlu direvitalisasi dikarenakan pasar rakyat memiliki kearifan lokal yang tidak dimiliki oleh pasar rakyat lain. Salah satunya yaitu segala aktivitas dalam pasar rakyat selalu dilandasi oleh ajaran agama hindu dan filosofi Tri Hita Karana. Pasar Rakyat memiliki potensi untuk dikembangkan menjadi pasar yang berbasis kepariwisataan budaya Bali. Kepariwisataan Budaya Bali selalu dikaitkan dengan tiga unsur yang erat kaitannya satu sama lain yaitu agama Hindu, adat istiadat masyarakat dan lembaga adat yang kemudian menghasilkan karya seni yang bernilai tinggi (Picard, 2006). Kebudayaan Bali, telah melekat pada kehidupan masyarakat Bali baik secara ekonomi maupun sosial. Pasar rakyat mencerminkan kehidupan masyarakat Bali, sekaligus menceminkan kebudayaan Bali. Sehingga, revitalisasi pasar rakyat bukan hanya merevitalisasi sebuah tempat tetapi merupakan salah satu upaya pemerintah dalam mempertahankan budaya dan ekonomi rakyat. 


\section{METODE PENELITIAN}

\section{Jenis data}

Penelitian ini menggunakan data kualitatif dan kuantitatif. Data kualitatif berupa keterangan narasi yang berhubungan dengan pengembangan pasar rakyat berbasis kepariwisataan budaya Bali.

\section{Sumber Data}

Sumber data yang dilakukan dalam penulisan penelitan ini adalah data sekunder. Data sekunder merupakan data yang diperoleh secara tidak lansung dari sumbernya yang mampu memberikan informasi penunjang. Informasi yang diperoleh berasal dari jurnal, buku-buku dan studi Pustaka lainnya.

\section{Metode Analisis Data}

\section{Metode Analisis Deskriptif - Kualitatif}

Penelitian ini menerapkan metode analisis deskriptif kualitatif. Dalam metode ini, data yang dikumpulkan melalui wawancara langsung dan data skunder dideskriptifkan secara menyeluruh (Prabowo, Aan, \& Heriyanto, 2013). Pada analisis deskriptif kualitatif, peneliti mengeksplorisasi dan atau memotret situasi sosial yang akan diteliti secara menyeluruh, luas, dan mendalam.

\section{HASIL DAN PEMBAHASAN}

Secara sejarah, pasar telah ada sejak abad ke-10, pada masa pemerintahan Mpu Sindook keberadaan pasar rakyat dikenal dengan istilah "Pkan". Pada masa tersebut, "Pkan" ini dikelola oleh pemerintahan untuk mengawasi, mengontrol dan mengendalikam "Pkan" (Firmanzah dan Halim, 2012).

"Pkan" berkontribusi pada kerajaan dalam bentuk pajak dan salah satu wujud kekuasaan politik. "Pkan" yang kemudian dikenal dengan pasar rakyat memiliki peran yang sangat penting bagi perekonomian kerajaan. Keberadaan pasar rakyat, yang pada saat itu pembayaran cara barter masih dilakukan selain pembayaran dengan uang, membuktikan bahwa konsep pasar rakyat merupakan mekanisme ekonomi paling tua dan sebagai pilar ekonomi suatu wilayah.

Peraturan Presiden No. 112 Tahun 2007 (Firmanzah dan Halim, 2012) menyebutkan bahwa pasar tradisional adalah pasar yang dibangun dan dikelola oleh 
pemerintah daerah, swasta, badan usaha milik negara dan badan usaha milik daerah, termasuk kerjasama antara pemerintah dan swasta, berupa toko, kios, los, dan tenda yang dimiliki atau dikelola oleh pengusaha dengan usaha mikro, kecil, menengah dan dalam proses jual beli barang dan jasa melalui tawar-menawar. Sesuai dengan Peraturan Menteri Perdagangan R.I Nomor : 56/M-DAG/PER/9/2014 istilah pasar tradisional berubah menjadi pasar rakyat dan toko modern berubah menjadi pasar swalayan.

Pasar rakyat merupakan suatu kegiatan ekonomi yang melibatkan berbagai elemen masyarakat. Sistem dalam pasar rakyat terdiri dari beberapa subsistem yang saling berinteraksi dan saling mempengaruhi. Subsistem tersebut adalah subsistem pengelola pasar, pegawai, pedagang/pengecer, pekerja/karyawan, pembeli, pemasok/agen, dan produsen.

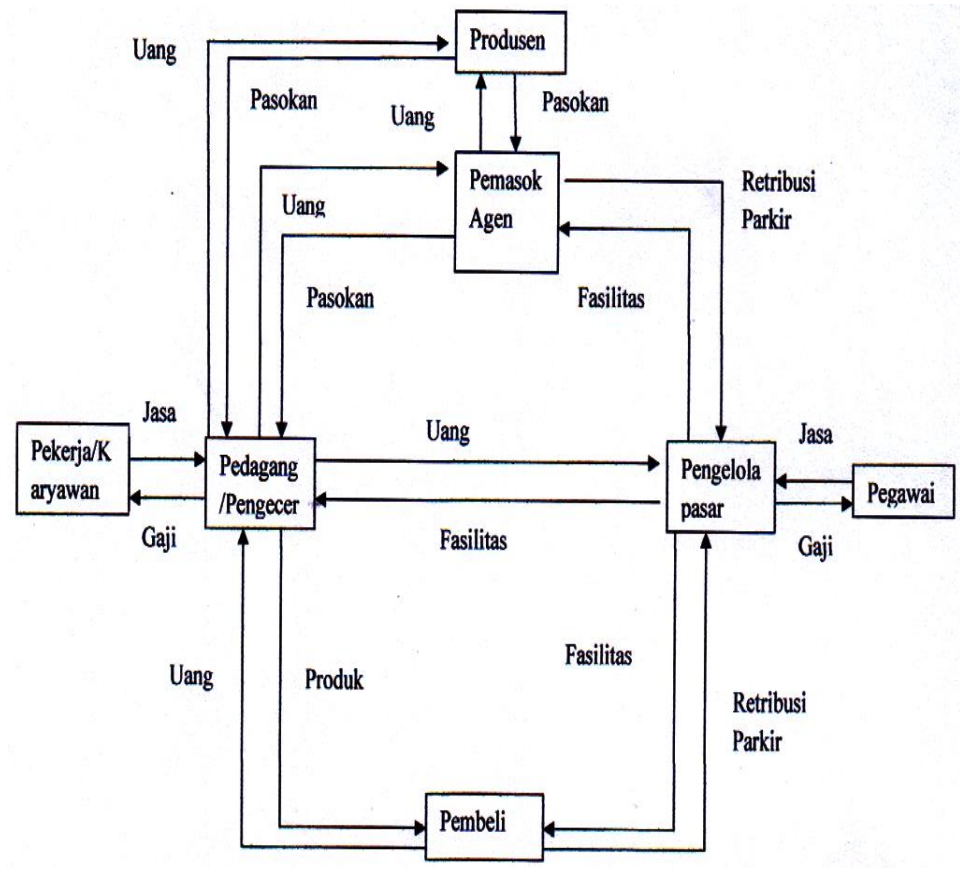

Gambar 1

Interaksi Antar Subsistem dalam Sistem Pasar Rakyat

(Firmanzah dan Halim, 2012)

\section{a. Pengelola Pasar}

Pengelola pasar adalah perusahaan daerah atau swasta. Pengelola tersebut membangun infrastruktur pasar dan bertanggung jawab dalam hal penyediaan fasilitasnya. Pengelola memiliki beberapa pegawai untuk membantu. Kios-kios dan los yang dibangun pengelola disewakan kepada para pedagang. 


\section{b. Pedagang}

Pedagang yang memiliki kios yang cukup besar biasanya memiliki karyawan/pekerja. Sebagian dari mereka memperoleh pasokan barang dari pemasok. Sebagian memperoleh pasokan lansung dari produsen. Pedagang merupakan pelaku agribisnis karena sebagian besar barang dagangan di pasar rakyat merupakan bahan keperluan sehari-hari seperti daging, beras dan sayur maupun pangan jadi.

\section{c. Pemasok}

Pemasok barang di pasar adalah agen yang mengambil barang dari produsen atau pedagang yang mengambil barang lansung dari produsen. Namun, ada beberapa kejadian pedagang bersifat proaktif, lansung mendatangi pemasok. Contoh produsen yaitu petani, peternak, dan produsen yang mengolah produk pertanian menjadi produk jadi maupun setengah jadi. Pedagang dapat membayar secara kontan atau kredit sesuai dengan perjanjian antara kedua belah pihak.

\section{d. Pembeli}

Pembeli di pasar rakyat sebagian besar tinggal di sekitar pasar. Para pembeli memiliki perilaku pembelian yang berbeda dalam berbelanja. Pada pasar rakyat produk yang dibeli yaitu bahan keperluan sehari-hari.

Sedangkan beberapa pembeli memberi keperluan bulanan di pasar modern. Secara umum pembeli terbagi menjadi dua kelompok.

1. Pembeli yang membeli barang untuk dikonsumsi sendiri. Misalnya ibu rumah tangga atau warga yang ingin menyelenggarakan suatu acara.

2. Pembeli yang membeli barang untuk dijual kembali. Barang yang dijual kembali tersebut ada yang diolah terlebih dahulu dan ada yang tidak diolah. Misalnya warung makan, tukang sayur keliling, tukang bakso, dan Iain-lain.

Secara garis besar lingkungan pasar rakyat terlihat pada Gambar 2. 


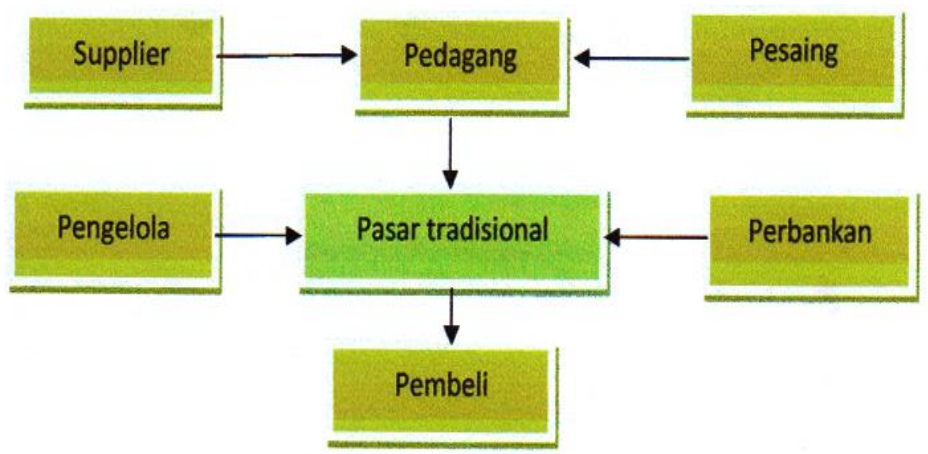

Gambar 2

Lingkungan Pasar Rakyat (Firmanzah dan Halim, 2012)

Pasar rakyat lebih kental dengan nilai-nilai kebersamaan antar pedagang dan nilai toleransi yang tinggi. Sebab secara tidak lansung pasar rakyat merupakan pusat ekonomi terbuka untuk rakyat dan pusat budaya yang mau tidak mau melibatkan aspek komunikasi literal, visual, verbal, dan non verbal antar sesama. Pasar rakyat, apabila dikupas secara mendalam, merupakan salah satu cermin filosofi. Cermin filosofi yang dimaksud yaitu demokrasi dan kearifan budaya lokal. Pasar rakyat di Indonesia cenderung mempunyai budaya sendiri yang berbeda antar pasar rakyat lainnya (Saputra, Haris, \& Wiharto, 2012).

Bali sebagai salah satu provinsi yang terkenal sebagai daerah pariwisata berpotensi mengembangkan pasar rakyatnya sebagai pasar wisata. Pasar Rakyat yang ada di pulau Bali mempunyai ciri khas budaya tersendiri yang berbeda dengan pasar rakyat lainnya di Indonesia. Ciri khas pasar rakyat di Bali yaitu filosofi Tri Hita Karana dan ajaran agama hindu yang ada disetiap aspek kegiatan pasar rakyat.

Pasar Rakyat di Bali sangat berpotensi dikembangkan menjadi pasar rakyat berbasis kepariwisataan budaya Bali. Sebagaimana yang tertuang pada Peraturan Daerah Provinsi Bali Nomor 2 Tahun 2012 tentang Kepariwisataan Budaya Bali, kepariwisataan budaya Bali berlandaskan kebudayaan Bali yang dijiwai oleh ajaran agama Hindu dan falsafah Tri Hita Karana sebagai potensi utama aktualisasinya. Dengan demikian, hubungan antara kepariwisataan dan kebudayaan membuat keduanya berkembang secara harmonis dan berkelanjutan yang berujung pada peningkatan kesejahteraan kepada masyarakat dan kelestarian budaya dan lingkungan.

Dalam mengembangkan pasar rakyat berbasis kepariwisataan budaya Bali, pasar rakyat harus memiliki standar yang ditetapkan oleh pemerintah (Peraturan Daerah Provinsi Bali, 2020). Standar kepariwisataan budaya Bali digunakan sebagai 
pedoman dan dasar penilaian penyelenggaraan kepariwisataan budaya Bali. Sedangkan penyelenggaraan budaya Bali adalah kegiatan kepariwisataan berbasis kearifan lokal yang meliputi produk, pelayanan, dan/atau pengelolaan.

Standar penyelenggaraan kepariwisataan budaya Bali disusun berdasarkan asas yang dijiawai oleh filosofi Tri Hita Karana yang bersumber dari kearifan lokal Sad Kerthi yang meliputi :
a. Ramah lingkungan
b. Keberlanjutan
c. Keseimbangan
d. Keberpihakan pada sumber daya local
e. Kemandirian
f. Kerakyatan
g. Kebersamaan
h. Partisipatif
i. Transparansi
j. Akuntabel dan
k. Manfaat

Peningkatan kualitas penyelenggaraan kepariwisataan Bali meliputi : (i) kualitas destinasi pariwisata; (ii) kualitas industri pariwisata; (iii) kualitas pemasaran pariwisata; (iv) kualitas kelembagaan pariwisata. Peninggkatan kualitas dicapai dengan peningkatan standar produk, pelayanan, sarana prasarana, keamanan, keselamatan, kesehatan dan pemanfaatan teknologi terkini. Penyelenggaraan kepariwisataan budaya Bali dapat dilakukan oleh pemerintah daerah, swasta, desa adat dan/atau masyarakat. Penyelenggaraan tersebut meliputi:
a. Perencanaan
b. Pembangunan
c. Pengembangan
d. Pengelolaan dan
e. Pengawasan

Penyelenggaraan kepariwisataan budaya Bali wajib memperhatikan: (i) kearifan lokal yang bersumber dari filosofi Tri Hita Karana berdasarkan nilai-nilai 
kearifan lokal Sad Kerthi; (ii) perlindungan lingkungan alam dan budaya Bali secara berkelanjutan; (iii) pemberdayaan potensi ekonomi masyarakat; (iv) pemenuhan standar keamanan, keselamtan, dan Kesehatan dan (v) usaha pariwisata berkelanjutan.

\section{KESIMPULAN}

Pengembangan Pasar Rakyat berbasis kepariwisataan budaya Bali yaitu sebuah rancangan mengembangkan pasar rakyat di Bali yang berbasis pada kepariwisataan budaya Bali. Dimana, kepariwisataan budaya Bali yaitu kepariwisataan Bali yang berlandaskan kepada kebudayaan Bali yang dijiwai oleh ajaran agama Hindu dan falsafah Tri Hita Karana. Yang dalam penyelengaraannya bersumber pada kearifan lokal Sad Kerthi.

\section{DAFTAR PUSTAKA}

Antara, M. (2009). Pertanian Bangkit atau Bangkrut? Denpasar: Arti Foundation. Biro Pusat Statistik. 2017. Gross Regional Domestik Bruto Provinsi Bali.

Firmanzah, \& Halim, R. . (2012). Strategi Revitalisasi Pasar Tradisional. In M. C. Basri (Ed.), Rumah Ekonomi Rumah Budaya. Jakarta: PT Gramedia Pustaka Utama.

Peraturan Daerah Provinsi Bali Nomor 2 Tahun 2012 tentang Kepariwisataan Budaya Bali.

Peraturan Daerah Provinsi Bali Nomor 5 Tahun 2020 tentang Standar Penyelengaraan Kepariwisataan Budaya Bali.

Peraturan Menteri Perdagangan Republik Indonesia Nomor: 56/M-DAG/PEK/9/2014 tentang Perubahan Atas Peraturan Menteri Perdagangan Nomor 70/MDAG/PER/12/2013.

Picard, M. (2006). Bali Pariwisata Budaya dan Budaya Pariwisata. Jakarta: KPG.

Prabowo, Aan, \& Heriyanto. (2013). Analisis Pemanfaatan Buku Elektronik (E-Book) oleh Pemustaka di Perpustakaan SMA Negeri 1 Semarang. Jurnal Ilmu Perpustakaan, 2(2), 1-9.

Saputra, Haris, \& Wiharto. (2012). Pasar Tradisional: Rumah Budaya dan Rumah Ekonomi. In M. . Basri (Ed.), Rumah Ekonomi Rumah Budaya. Jakarta: PT Gramedia Pustaka Utama. 